\title{
Hypericin-mediated photodynamic therapy induces apoptosis in K562 human leukemia cells through JNK pathway modulation
}

\author{
YIXIAO XU ${ }^{1,2^{*}}$, DEXUAN WANG ${ }^{3 *}$, ZHIZHI ZHUANG ${ }^{3}$, KEKE JIN $^{2}$, \\ LVZHEN ZHENG $^{2}$, QING YANG ${ }^{3}$ and KUNYUAN GUO ${ }^{1}$
}

\author{
${ }^{1}$ Department of Hematology, Zhujiang Hospital, Southern Medical University, Guangzhou, Guangdong 510282; \\ ${ }^{2}$ Department of Pathophysiology, Wenzhou Medical University, Wenzhou, Zhejiang 325035; ${ }^{3}$ Department of Pediatrics, \\ The Second Affiliated and Yuying Children's Hospital of Wenzhou Medical University, \\ Wenzhou, Zhejiang 325000, P.R. China
}

Received November 7, 2014; Accepted July 28, 2015

DOI: $10.3892 / \mathrm{mmr} .2015 .4258$

\begin{abstract}
Hypericin (Hyp) is traditionally used as an antidepressant and antiviral agent. It selectively accumulates in spheroids and is also used as a photosensitizer in the photodynamic therapy of cancer. The present study aimed to investigate the cytotoxic effect of Hyp-mediated photodynamic therapy (Hyp-PDT) on cell growth and apoptosis of K562 leukemia cells, and to examine the underlying mechanisms. Hyp-PDT was performed with different light intensities $\left(0.1,0.3\right.$ and $\left.0.5 \mathrm{~mW} / \mathrm{cm}^{2}\right)$, different concentrations of Hyp (0, 0.2, 0.4 and $0.8 \mu \mathrm{g} / \mathrm{ml})$ and different durations of irradiation $(0,2,4$ and $8 \mathrm{~min})$ in order to select the optimal conditions for subsequent experiments. A concentration of $0.4 \mu \mathrm{g} / \mathrm{ml}$ Hyp with a $5 \mathrm{~h}$ drug-light interval and $4 \mathrm{~min}$ irradiation at $0.3 \mathrm{~mW} / \mathrm{cm}^{2}$ light intensity was selected as the optimal conditions. The effects of Hyp-PDT on apoptosis were determined by detecting morphological changes under microscopy and by performing western blot analysis. The results revealed that Hyp-PDT suppressed cell viability in a light intensity-, dose- and irradiation duration-dependent manner. The expression levels of cleaved caspase- 9 , cleaved caspase-3 and phosphorylated-C-Jun N terminal kinase (JNK) 1 were significantly upregulated following Hyp-PDT. These results indicated that Hyp-PDT decreased cell viability and induced mitochondria-caspase-dependent apoptosis in the K562 cells through regulation of the JNK pathway. These findings suggest that Hyp-PDT may be developed as an effective treatment for leukemia.
\end{abstract}

Correspondence to: Professor Kunyuan Guo, Department of Hematology, Zhujiang Hospital, Southern Medical University, 253 Industrial Road, Guangzhou, Guangdong 510282, P.R. China

E-mail: kunyuanguo@hotmail.com

*Contributed equally

Key words: photodynamic therapy, hypericin, K562, apoptosis, C-Jun $\mathrm{N}$ terminal kinase

\section{Introduction}

Photodynamic therapy (PDT) is a cytotoxic treatment induced by light interactions, cell or tissue molecular oxygen and photosensitizing molecules, termed the photosensitizer (PS) (1). Once irradiated by visible light, the PS can react through two photo-oxidative pathways, classified as type I and type II (2). The type I pathway involves the generation of free radicals through PS or a substrate. These radicals react twith oxygen, resulting in the generation of reactive oxygen species (ROS), including superoxide anion, hydrogen peroxide nd hydroxyl radicals. In the type II pathway, the PS directly transfers energy to oxygen to produce ${ }^{1} \mathrm{O}_{2}$, which induces apoptosis. These two pathways can lead to oxidative damage and ultimately to cell damage, including apoptotic, autophagic and/or necrotic cell death $(3,4)$. PDT has been used for treating various types of malignancy, including bladder cancer, Barrett's esophagus, unresectable cholangiocarcinoma and skin cancer (4-6). Compared with conventional cancer treatment modalities, PDT has several advantages, including high sensitivity to tumor tissues, minimal side effects and possible repetitive cycles of treatment, and the potential for combination with other forms of therapy, including chemotherapy and radiotherapy (7).

Among the factors affecting the efficacy of PDT, PS is of importance. Hypericin (Hyp), with a typical naphthodianthrone structure, is the predominant active component of Hypericum species; commonly known as Hypericumperforatum or St. John's wort (8). For decades, Hyp has been used as a drug treatment for depression and viruses. It is also one of the most potent PSs, which has a maximum absorption peak of $\sim 599 \mathrm{~nm}$ (9) and has several advantages over other PSs, including substantial quantum yield, intense absorption spectrum in the visible region, low photobleaching and a large excitation range (10). At low concentrations, Hyp induces apoptosis mediated by ${ }^{1} \mathrm{O}_{2}$; whereas, at high concentrations, it tends to induce necrosis via other ROS (11). Although, it has not yet been approved for clinical application, several studies have demonstrated that Hyp-PDT has high tumor-specific cytotoxicity and minimal side effects $(12,13)$. 
Physiologically, programmed cell death or apoptosis is important in eliminating aging and damaged cells. It is involved in development and tumorigenesis; and for the latter, cells lose their ability to undergo apoptosis due to a variety of environmental and genetic factors (14). Therefore, in addition to restricting cancer cell proliferation and metastasis, promoting cancer cell apoptosis is also a valid approach in cancer therapy. It has been demonstrated that apoptosis, secondary to the increase in ROS, is a predominant mechanism of action in Hyp-PDT, and it has been suggested that the mitochondrial-mediated (intrinsic) pathway (15) and the death receptor-mediated (extrinsic) pathway (16) are involved in Hyp-PDT-induced apoptosis.

However, the efficacy and safety of Hyp-PDT in leukemia treatment remains to be fully elucidated. Hyp selectively accumulates in spheroids (17). In our previous preliminary experiment, it was observed that Hyp-PDT in the extracorporeal circulation of normal Sprague-Dawley rats resulted in marked white blood cell reduction, while red blood cells generally remained intact. Therefore, it was hypothesized that Hyp-PDT may be developed as a novel therapy for leukemia, if the efficacy and safety can be demonstrated in clinical relevant models. In the present study, the K562 cell line was established from the pleural effusion of patients with chronic myeloid leukemia (CML) at the blast crisis phase. With a high activity of BCR-ABL protein tyrosine kinase, the K562 cell has been reported to resist the induction of apoptosis by several stimuli (18). The present study aimed to demonstrate the influence that Hyp-PDT had on K562 leukemia cells and the possible pathway involved, so as to investigate an effective treatment or complementary therapy for leukemia, including for patients with CML in blast crisis.

\section{Materials and methods}

Chemicals andreagents.Hyp with a purity of $95 \%$ and dimethyl sulfoxide (DMSO) were purchased from Sigma-Aldrich (St. Louis, MO, USA). The cell culture medium (RPMI 1640) and penicillin-streptomycin were purchased from Gibco Life Technologies (Carlsbad, CA, USA). Fetal bovine serum (FBS) was purchased from GE Healthcare Life Sciences (Logan, UT, USA). The Cell-Counting Kit-8 (CCK-8) was purchased from Dojindo Laboratories (Kyushu, Japan). Rabbit anti-human antibodies against C-Jun $\mathrm{N}$ terminal kinase (JNK) (cat. no. 9252, 1:1,000), phosphorylated (p) JNK (cat. no. 4668, 1:1,000), caspase 9 (cat. no. 9508, 1:1,000), caspase 3 (cat. no. 9665, 1:1,000), and cleaved caspase 3 (cat. no. 9664, 1:1,000) were purchased from Cell Signaling Technology, Inc. (Danvers, MA, USA). Mouse anti-human anti-GAPDH monoclonal antibody (cat. no. E021010, 1:1,000) was supplied by EarthOX Company (San Francisco, CA, USA). Goat anti-rabbit secondary antibody (cat. no. 103349, 1:12,000) was purchased from Jackson ImmunoResearch Laboratories, Inc (West Grove, PA, USA). RIPA buffer was purchased from Sigma-Aldrich. SDS-PAGE gel and PVDF membrane were from Bio-Rad Laboratories, Inc. (Hercules, CA, USA). Glutaraldehyde, osmium tetroxide, lead citrate and uranyl acetate were purchased from Rongbai Biological Technology Co., Ltd. (Shanghai, China). All other reagents were of analytical grade.
Cell culture. The K562 human CML cell line K562 was purchased from the Cell Resource Center, Institute of Chinese Academy of Medical Sciences (Shanghai, China). The cells were cultured in RPMI 1640 medium containing 10\% FBS, penicillin $(100 \mathrm{U} / \mathrm{ml})$ and streptomycin $(100 \mu \mathrm{g} / \mathrm{ml})$ at $37^{\circ} \mathrm{C}$, in a $5 \% \mathrm{CO}_{2}$ humidified atmosphere. Exponentially growing cells were used for the following experiments, with a cell density of $\sim 4 \times 10^{5}$ cells $/ \mathrm{ml}$. The stock solution of Hyp $(0.8 \mu \mathrm{g} / \mathrm{ml})$ was prepared by dissolving the compound in DMSO, which was then maintained in the dark at $-4^{\circ} \mathrm{C}$. The Hyp working solution for each experiment was freshly diluted with DMSO priot to its addition to the K562 suspension; and the final DMSO concentration in all cultures was $0.1 \%$.

PDT procedure. ABHY-Y50 W matrix LED lamp(Baihuixiang Electric Co., Ltd., Shenzhen, China), with a maximum power of $50 \mathrm{~W}$, was used as a light source, having a maximum peak value of $595.18 \mathrm{~nm}$ (measured by the Department of Physics, Wenzhou University, Wenzhou, Zhejiang, China). The light intensity of the led lamp was adjustable between 0.1 and $40 \mathrm{~mW} / \mathrm{cm}^{2}$. The K562 suspensions were incubated with Hyp or DMSO (as a control) for $5 \mathrm{~h}$; and were then exposed and irradiated under a matrix led lamp for $4 \mathrm{~min}$.

Cell survival assay. Cell viability was measured using a CCK8 assay. To examine the effectiveness of Hyp-PDT at moderate light intensity, the cells were seeded into 96-well plates, cultured overnight and exposed to a Hyp solution $(0.4 \mu \mathrm{g} / \mathrm{ml})$; using a similar in vitro Hyp-PDT procedure as that performed previously in the U937 human leukemic monocyte lymphoma cell line (9). Irradiation was performed for $4 \mathrm{~min}$ with 0.1 , 0.3 and $0.5 \mathrm{~mW} / \mathrm{cm}^{2}$ light intensities on the sample surface. Subsequently, $10 \mu \mathrm{l}$ CCK8 solution was added to each well prior to irradiation, 5 min following irradiation, and 4, 8 and $16 \mathrm{~h}$ following irradiation, respectively. The cells were incubated for an additional $2 \mathrm{~h}$ at $37^{\circ} \mathrm{C}$. The optical density (OD) was then measured at $450 \mathrm{~nm}$ using a microplate reader (550; Bio-Rad Laboratories, Inc.). Cell viability was calculated as follows: Cell viability $\left.=\left(\mathrm{OD}_{\text {test }}-\mathrm{OD}_{\text {blank }}\right) / \mathrm{OD}_{\text {control }}-\mathrm{OD}_{\text {blank }}\right)$ $\mathrm{x} 100 \%$.

In order to determine the effects of the different Hyp concentrations at various irradiation durations on the K562 cells, a CCK8 assay was performed with a series of Hyp concentrated solutions $(0,0.2,0.4$ and $0.8 \mu \mathrm{g} / \mathrm{ml}$, respectively) and at various irradiation durations $(0,2,4$ and $8 \mathrm{~min}$, respectively), using a light intensity of $0.3 \mathrm{~mW} / \mathrm{cm}^{2}$ at different time-points (pre-irradiation, and $5 \mathrm{~min}, 4,8$ and $16 \mathrm{~h}$ post-irradiation).

Western blot analysis. PDT with 4 min irradiation at a light intensity of $0.3 \mathrm{~mW} / \mathrm{cm}^{2}$ was applied to the Hyp-treated K562 cells $(0.4 \mu \mathrm{g} / \mathrm{ml})$ for $5 \mathrm{~h}$, and the control cells were treated with DMSO only for $5 \mathrm{~h}$. Cell lysates were then prepared, and total proteins were extracted at various time-points (prior to irradiation, and 4,8 , and 16 h post-irradiation). Western blot analysis was then performed. In brief, the K562 cells were gently washed thee times with cold phosphate-buffered saline (PBS) and then lysed with radioimmunoprecipitation assay lysate buffer containing $1 \mathrm{mmol} / \mathrm{l}$ phenylmethylsulfonyl fluoride and $10 \mathrm{mmol} / \mathrm{l}$ of $\mathrm{NaF}$ for $30 \mathrm{~min}$ on ice. The cell lysates were then centrifuged at 7,200 x g for $15 \mathrm{~min}$ at 

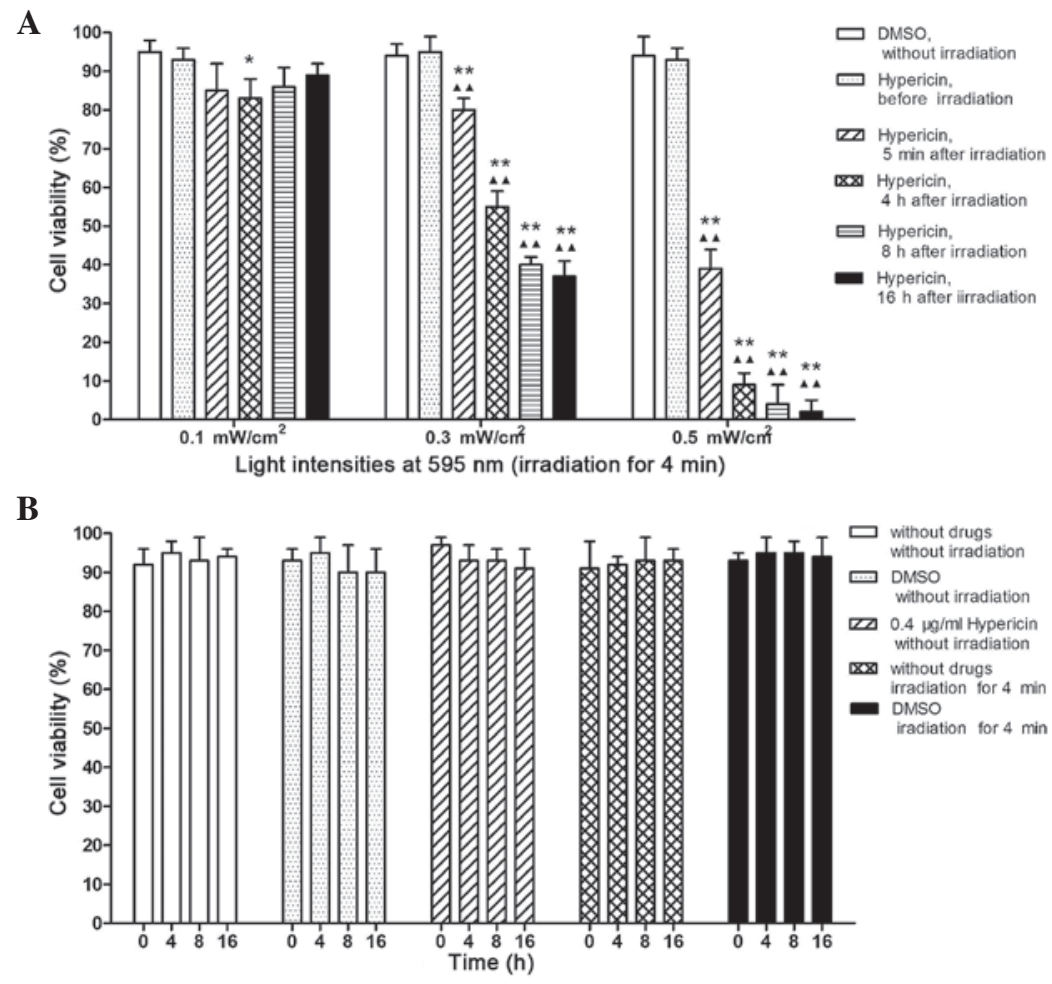

Figure 1. Viability of K562 cells treated with Hyp-PDT under various conditions. (A) Cell viability of samples incubated in $0.4 \mu \mathrm{g} / \mathrm{ml} \mathrm{Hyp}$ for $5 \mathrm{~h}$ prior to irradiating for 4 min using an LED lamp (maximum peak value, $595.18 \mathrm{~nm}$ ) with $0.1,0.3$ and $0.5 \mathrm{~mW} / \mathrm{cm}^{2}$ adjusted light intensities, at different time-points (5 min-16 h post-irradiation). K562 cells treated with Hyp or DMSO alone without irradiation were used as controls. Each experiment was repeated three times and data are expressed as the mean \pm standard deviation. (B) Cell viability of control cells. The cells were incubated for $5 \mathrm{~h}$ with either DMSO alone, $0.4 \mu \mathrm{g} / \mathrm{ml}$ Hyp or with no treatment. For cells treated with PTD, the cells were exposed to irradiation for 4 min with $0.3 \mathrm{~mW} / \mathrm{cm}^{2}$ light intensity. No significant differences were observed between the controls at any time-point. " $\mathrm{P}<0.05$, compared with untreated control; ${ }^{* *} \mathrm{P}<0.01$, compared with untreated control; ${ }^{\Delta \Delta} \mathrm{P}<0.01$, compared with cells treated with $0.4 \mu \mathrm{g} / \mathrm{ml}$ Hyp, but without irradiation. PTD, photodynamic therapy; Hyp, hypericin; DMSO, dimethyl sulfoxide.

$4^{\circ} \mathrm{C}$ and the supernatants were collected. Equal quantities of protein $(40 \mu \mathrm{g})$ were separated by SDS-PAGE $(8 \%)$ and transferred onto a polyvinylidene difluoride membrane. The membrane was blocked with 5\% skim milk in Tris-buffered saline with Tween $(0.05 \%$; TBST) for $1 \mathrm{~h}$ at room temperature. After washing for 15 min with TBST 3 times, the membrane was immunoblotted with antibodies against JNK, p-JNK, caspase 9 , caspase 3 and cleaved caspase 3 at $4^{\circ} \mathrm{C}$ overnight. Subsequently, the membrane was incubated with the secondary antibody for $2 \mathrm{~h}$ at room temperature after washing for $15 \mathrm{~min}$ with TBST 3 times. The protein of interest was identified using an enhanced chemiluminescence system (GE Healthcare Life Sciences). All experiments were repeated thee times.

Observation of cell morphology using microscopy. Cell morphology was examined under a light microscope and a transmission electron microscope. The K562 cells were first observed under a Leica DMR-HC (Leica Microsystems GmbH, Wetzlar, Germany) upright research microscope, and microscopic images were captured using Openlab imaging software, version 5.5.2 (PerkinElmer, Inc., Waltham, MA, USA). For transmission electron microscopic observation, the cells were fixed with $2 \%$ glutaraldehyde and $1 \%$ osmium tetroxide; and dehydrated in graded ethanol solutions. Following embedding in TAAB 812 epoxy resin (TAAB Laboratories Equipment, Ltd., Aldermaston, UK) ultrathin $80 \mathrm{~nm}$ sections were produced using a Reichert Ultracut E Ultramicrotome (Leica, Vienna, Austria). Following staining with $1 \%$ lead citrate and
$2 \%$ alcoholic uranyl acetate, the sections were examined under a Philips CM-12 electron microscope (Philips, Amsterdam, Netherlands) at $80 \mathrm{kV}$.

Statistical analysis. Experimental data were analyzed using SPSS 17.0 software (SPSS, Inc., Chicago, IL, USA). The data are expressed as the mean \pm standard deviation of three experiments. The differences between two groups were assessed using Student's $t$-test; $\mathrm{P}<0.05$ was considered to indicate a statistically significant difference.

\section{Results}

Effects of Hyp-PDT on cell viability. Fig. 1A shows the results of the cell viability assessment. The cells were incubated in $0.4 \mu \mathrm{g} / \mathrm{ml}$ Hyp for $5 \mathrm{~h}$, followed by $4 \mathrm{~min}$ of irradiation using an LED lamp (maximum peak value, $595.18 \mathrm{~nm}$ ) at $0.1,0.3$ and $0.5 \mathrm{~mW} / \mathrm{cm}^{2}$ adjusted light intensities at different time-points (Pre-irradiation; $5 \mathrm{~min}$, and 4, 8 and $16 \mathrm{~h}$ post-irradiation). Hyp-PDT with 0.3 and $0.5 \mathrm{~mW} / \mathrm{cm}^{2}$ light intensities significantly decreased cell viability at different time-points post-irradiation (all $\mathrm{P}<0.01)$. However, the decrease in cell viability was only observed $4 \mathrm{~h}$ post-irradiation with a $0.1 \mathrm{~mW} / \mathrm{cm}^{2}$ light intensity $(\mathrm{P}<0.05)$. Furthermore, cell viability at low light intensity $\left(0.1 \mathrm{~mW} / \mathrm{cm}^{2}\right)$ was marginally increased following longer incubation periods $(8$ and $16 \mathrm{~h}$ post-irradiation); however, the differences were not statistically significant. According to the results above, Hyp-PDT with 
A
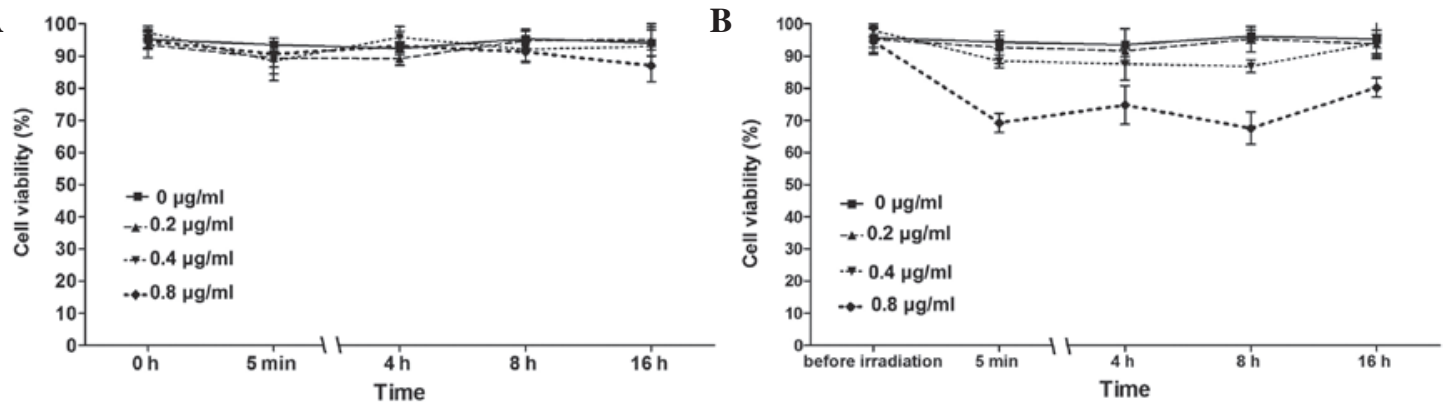

C

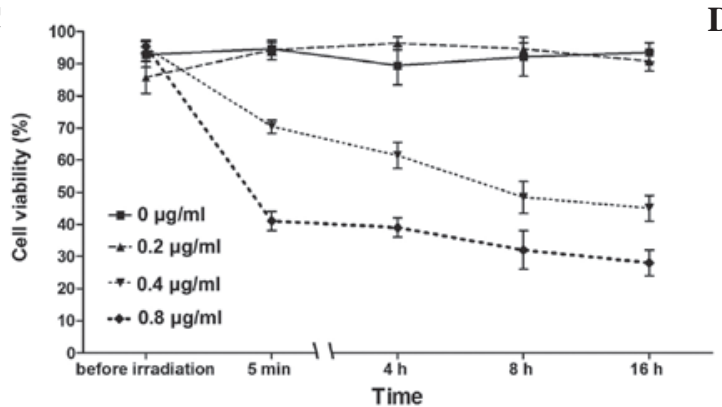

D

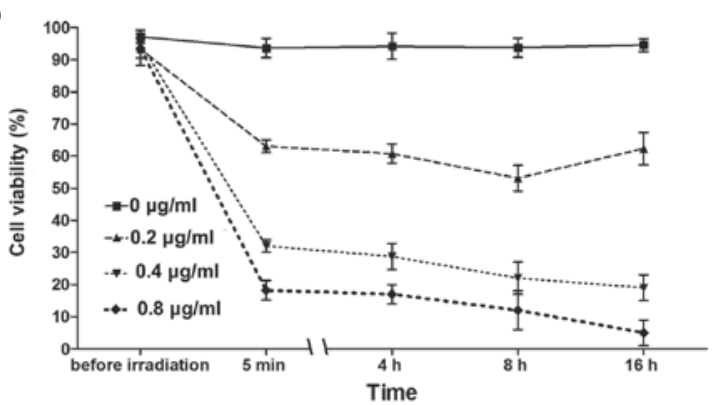

Figure 2. Hyp-photodynamic therapy effects on cell viability. K562 cells were treated with various concentrations of Hyp $(0,0.2,0.4$ and $0.8 \mu \mathrm{g} / \mathrm{ml})$ with $0.3 \mathrm{~mW} / \mathrm{cm}^{2}$ light intensity for various irradiation durations ( $0,2,4$ and $\left.8 \mathrm{~min}\right)$ at different time-points (pre-irradiation; and $5 \mathrm{~min}, 4,8$ and $16 \mathrm{~h}$ post-irradiation), (A) K562 cells treated with different concentrations of Hyp prior to irradiation. (B) K562 cells treated with different concentrations of Hyp and irradiated for 2 min. (C) K562 cells treated with different concentrations of Hyp and irradiated for 4 min. (D) K562 cells treated with different concentrations of Hyp and irradiated for $8 \mathrm{~min}$. Hyp, hypericin; DMSO.

$0.3 \mathrm{~mW} / \mathrm{cm}^{2}$ light intensity exhibited significant but moderate cell damage and was selected for the subsequent experiments. No significant changes were observed in the control cells at different time-points (Fig. 1B).

Under PDT conditions of $0.3 \mathrm{~mW} / \mathrm{cm}^{2}$ light intensity, the cell viability of the samples was analyzed at a series of Hyp concentrations $(0,0.2,0.4$ and $0.8 \mu \mathrm{g} / \mathrm{ml})$ durations of irradiation (0, 2, 4 and $8 \mathrm{~min}$ ) and time-points (pre-irradiation; $5 \mathrm{~min}$ post-irradiation; and 4, 8 and $16 \mathrm{~h}$ post-irradiation). As shown in Fig. 2, neither Hyp without irradiation (Fig. 2A) nor irradiation without Hyp, had any effects on the K562 cells. Overall, Hyp-PDT was observed to affect cell viability in a dose- and irradiation-time-dependent manner; with the lowest cell viability $(5 \%)$ observed in the cells treated with $0.8 \mu \mathrm{g} / \mathrm{ml}$ Hyp under $8 \mathrm{~min}$ of irradiation. However, the cells treated with $0.2 \mu \mathrm{g} / \mathrm{ml}$ Hyp resulted in minimal effects on cell viability (Fig. 2B and C); although moderate effects were observed after 8 min of irradiation (Fig. 2D).

Hyp-PDT-induced cellular morphological and structural changes. As shown in Fig. 3, morphological observation under a phase-contrast microscope confirmed the cytotoxic effect of Hyp-PDT on the K562 cells. Translucent spheroids with uniform profiles, growing in isolated or scattered colonies, were observed in the control K562 cells treated with DMSO alone (Fig. 3A). Following Hyp-PDT (Fig. 3B and C), the cells began to float on the culture medium and started to lose cell-to-cell contact. It also appeared that the cells underwent cell death and cell intensity decreased, compared with the control cells (Fig. 3D).

Transmission electron microscopy analysis demonstrated normal cell morphology in the control K562 cells treated with
DMSO alone (Fig. 4A). The absence of irradiation predominantly reflected intact cell and nuclear membranes and an evident nucleus with nuclear material. Normal organelles were identified in the cytoplasm, consisting of mitochondria, endoplasmic reticulum and lysosomes (Fig. 4B). Following Hyp-PDT $(0.4 \mu \mathrm{g} / \mathrm{ml} \mathrm{Hyp;} 5 \mathrm{~h}$ drug light duration; 4 min irradiation with $0.3 \mathrm{~mW} / \mathrm{cm}^{2}$ light intensity), the cells presented typical apoptotic cell characteristics, including chromatin condensation, agglomeration at the central nuclear area or gathering at the periphery to form crescents, a concentrated cytoplasm, bubble-like protrusions on the cell surface and the formation of apoptotic bodies (Fig. 4C). Apoptotic changes were more frequent over time, and numerous cells exhibiting loss of intracellular detail were clearly observed $16 \mathrm{~h}$ after Hyp-PDT (Fig. 4D).

Hyp-PDT-induced changes in apoptosis-associated proteins. Following incubation for $5 \mathrm{~h}$ with $0.4 \mu \mathrm{g} / \mathrm{ml}$ Hyp and irradiating for $4 \mathrm{~min}$ with $0.3 \mathrm{~mW} / \mathrm{cm}^{2}$ light intensity, the expression of cleaved caspase- 9 began to appear $4 \mathrm{~h}$ post-irradiation; which significantly increased 8 and $16 \mathrm{~h}$ post-irradiation. The appearance of the processed fragments was accompanied by a decrease in total capsase-9. Cleaved caspase- 3 was observed 8 h post-irradiation and was significantly upregulated at $16 \mathrm{~h}$, with a corresponding decrease of total caspase-3 at $16 \mathrm{~h}$ post-irradiation (Fig. 5). Treatment with either Hyp or irradiation alone had no effect on the expression levels of total or cleaved caspase- 9 or caspase- 3 in the control K562 cells.

Hyp-PDT-induced upregulation of $P$-JNK. In order to investigate the effect of Hyp-PDT on JNK, the protein expression 
A
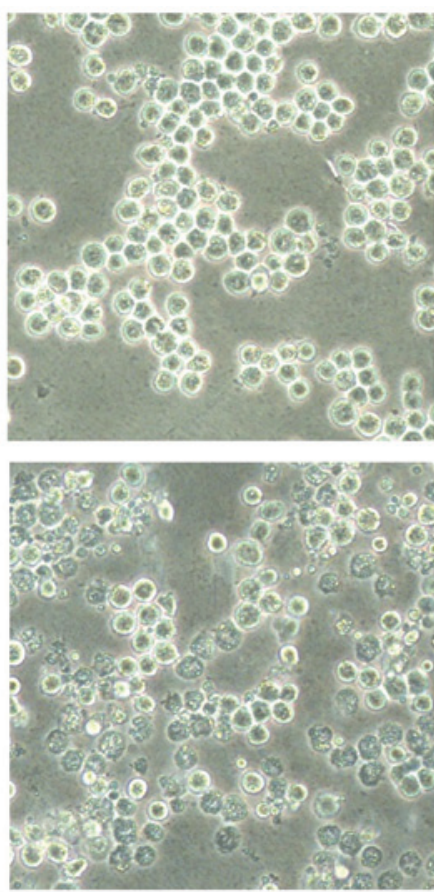

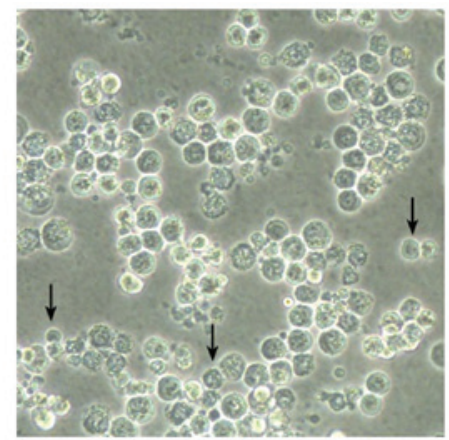

D

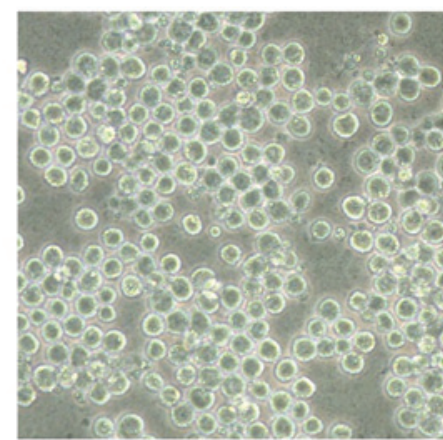

Figure 3. Phase-contrast microscopic images of K562 cells treated with Hyp-PDT (magnification, $\mathrm{x} 400$ ). The K562 cells were incubated with DMSO alone (control cells) or with $0.4 \mu \mathrm{g} / \mathrm{ml}$ Hyp (Hyp-PDT-reated cells) for $5 \mathrm{~h}$; and exposed to irradiation for 4 min using an LED lamp at $0.3 \mathrm{~mW} / \mathrm{cm}^{2}$ light intensity. (A) Control cells prior to irradiation. (B) Hyp-PDT-treated K562 cells $8 \mathrm{~h}$ post-irradiation. (C) Hyp-PDT-treated K562 cells 16 h post-irradiation. (D) K562 cells cultured for $16 \mathrm{~h}$ without any treatment. The black arrows in indicate cells exhibiting severe deformation and cell shrinkage. PTD, photodynamic therapy; Hyp, hypericin.
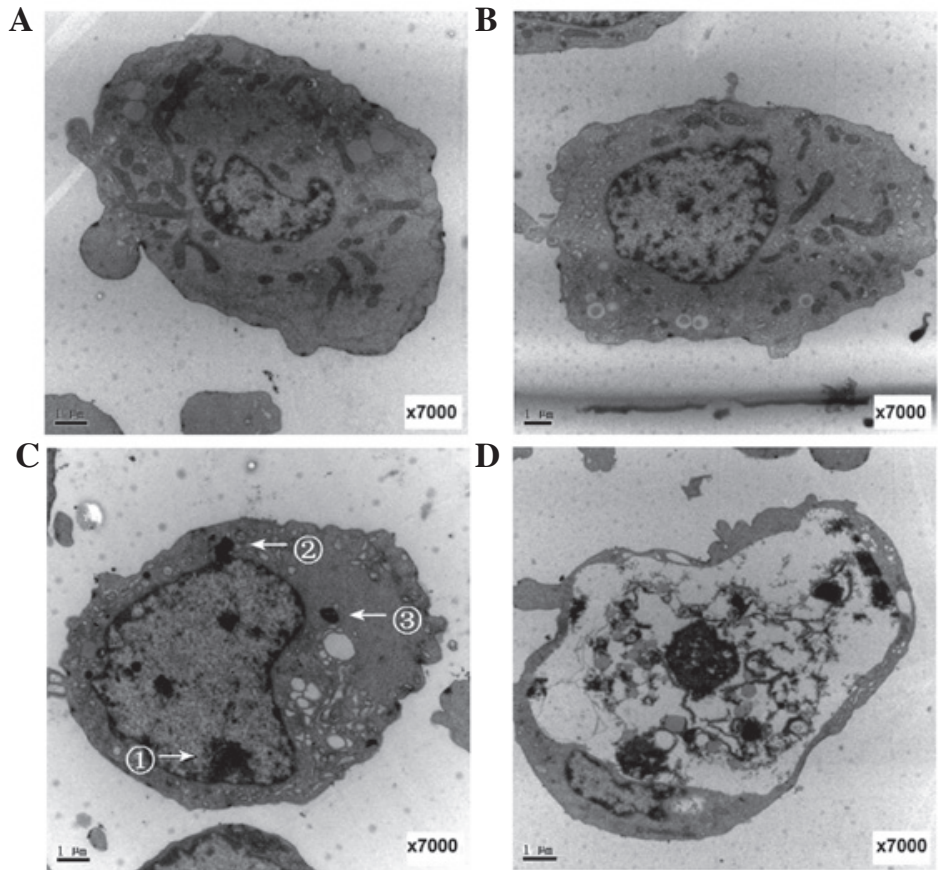

Figure 4. Transmission electron micrographs of K52 cells. (A) K562 cells treated with dimethyl sulfoxide alone; (B) K562 cells incubated with $0.4 \mu \mathrm{g} / \mathrm{ml} \mathrm{Hyp}$ for $5 \mathrm{~h}$ without irradiation; (C) K562 cells $4 \mathrm{~h}$ post-Hyp-PDT $\left(0.4 \mu \mathrm{g} / \mathrm{ml} \mathrm{Hy} ; 5 \mathrm{~h}\right.$ drug light interval; $5 \mathrm{~min}$ irradiation with $0.3 \mathrm{~mW} / \mathrm{cm}^{2}$ light intensity) presenting with typical apoptotic characteristics of chromatin agglomeration at the central nuclear area or at the periphery (arrow 1) and formation of apoptotic bodies (arrows 2 and 3). (D) K562 cells at $16 \mathrm{~h}$ post-Hyp-PDT, presenting with chromatin condensation and loss of intracellular details. PTD, photodynamic therapy; Hyp, hypericin.

level of JNK and its phosphorylated products were determined prior to irradiation, and 4,8 and $16 \mathrm{~h}$ post-irradiation, respectively. As shown in Fig. 6, Hyp-PDT significantly promoted JNK phosphorylation, the expression of which peaked at $4 \mathrm{~h}$ post-irradiation with a subsequent marginal decrease. No significant changes in the protein levels of total 


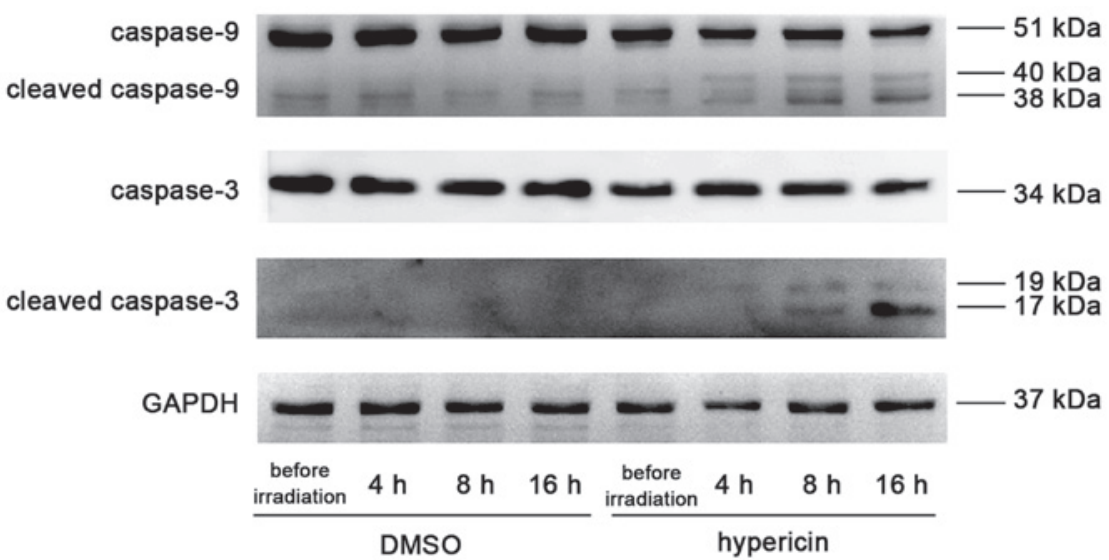

Figure 5. Effects of Hyp-mediated photodynamic therapy on caspase activation in K562 cells. K562 cells were incubated in $0.4 \mu \mathrm{g} / \mathrm{ml} \mathrm{Hyp}$ for $5 \mathrm{~h}$ prior to irradiating for $4 \mathrm{~min}$ at $0.3 \mathrm{~mW} / \mathrm{cm}^{2}$ light intensity. Protein expression levels of total and cleaved caspase- 9 and caspase-3 were determined pre-irradiation, and 4,8 and $16 \mathrm{~h}$ post-irradiation by western blot analysis. Hyp, hypericin.

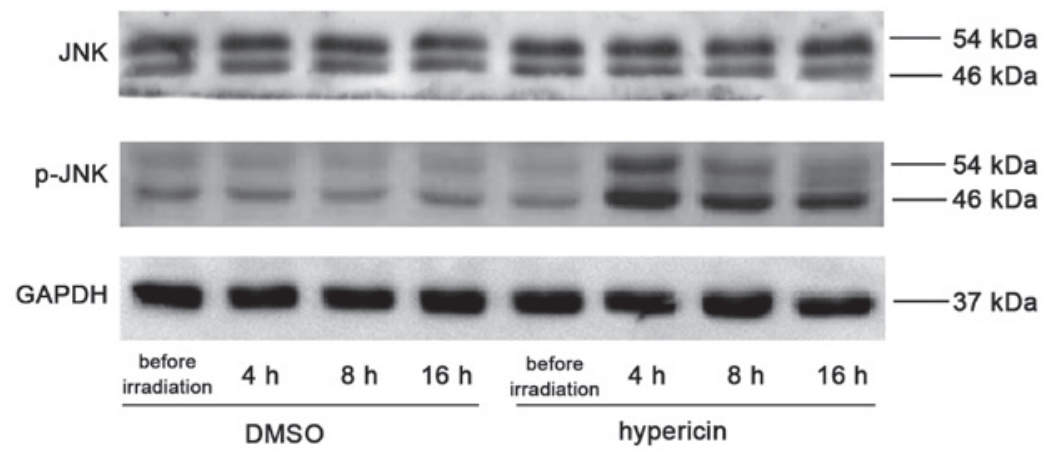

Figure 6. Effects of Hyp-mediated photodynamic therapy on JNK activation in K562 cells. K562 cells were incubated with $0.4 \mu \mathrm{g} / \mathrm{ml} \mathrm{Hyp}$ for 5 h prior to irradiating for 4 min with $0.3 \mathrm{~mW} / \mathrm{cm}^{2}$ adjusted light intensity. The protein expression levels of JNK and its phosphorylated product, p-JNK, were determined pre-irradiation, and 4, 8 and 16 h post-irradiation. Hyp, hypericin; JNK C-Jun N terminal kinase; p-, phosphorylated; DMSO, dimethyl sulfoxide.

JNK were observed in the Hyp-alone treated and control cells.

\section{Discussion}

In previous years, investigations and clinical trials have revealed that Hyp-PDT exerts potent phototoxicity in cancer cells (8). Hyp-PDT induces almost complete apoptosis (94\%) in malignant cutaneous T cell lymphoma (CTCL) cells (19). A phase II placebo-controlled clinical study performed by Rook et al (20) revealed that Hyp-PDT led to the significant improvement of skin lesions, among the majority of patients with CTCL investigated.

In order to demonstrate the effects of Hyp-PDT on K562 cells and to develop an optimal PDT protocol, the present study performed Hyp-PDT experiments using different light intensities, different concentrations of Hyp and different durations of irradiation. Briefly, Hyp-PDT with a $5 \mathrm{~h}$ drug-light-interval (10) exerted substantial phototoxicity in the K562 cells in a light-intensity-, Hyp-dose- and irradiation-time-dependent manner. Cell viability decreased to $5 \%$ in the presence of $0.8 \mu \mathrm{g} / \mathrm{ml} \mathrm{Hyp}$, following $8 \mathrm{~min}$ of irradiation with $0.3 \mathrm{~mW} / \mathrm{cm}^{2}$ light intensity (Figs. 1 and 2). However, the effects were minimal at a low light intensity $\left(0.1 \mathrm{~mW} / \mathrm{cm}^{2}\right)$, low Hyp concentration $(0.2 \mu \mathrm{g} / \mathrm{ml})$ and short irradiation duration
( $2 \mathrm{~min}$ ). A Hyp concentration of $0.4 \mu \mathrm{g} / \mathrm{ml}$ with a $5 \mathrm{~h}$ drug-light interval, $4 \mathrm{~min}$ irradiation duration and $0.3 \mathrm{~mW} / \mathrm{cm}^{2}$ light intensity were selected for subsequent experiments; as these conditions resulted in significant but moderate cell damage, and the side effects were significantly reduced. The reduction in cell population reduction and morphological changes observed under a light microscope confirmed the cell cytotoxicity results.

Furthermore, the condensation and loss of intracellular details observed in the cells under an electron microscope clearly demonstrated that apoptosis occurred following Hyp-PDT. In accordance with these cellular structural changes, the levels of cleaved caspase-3 and cleaved caspase- 9 significantly increased following Hyp-PDT. Caspases are a family of cysteine proteases and are key mediators of apoptosis. It has been demonstrated that Hyp-PDT-induced apoptosis is predominantly executed via the mitochondrial-mediated apoptotic cascade and can be triggered directly at the mitochondria (21) or by the endoplasmic reticulum-stress response (22). As verified using a cDNA macroarray and reverse transcription-quantitative polymerase chain reaction analysis, A-431 human squamous carcinoma cells undergo apoptosis within 1.5-8 h following Hyp-PDT (23). This was confirmed through the reduction in extracellular signal transduction, cell detachment changes in cytoskeletal morphology, and the formation 
of apoptotic bodies. Following the production of ROS, mitochondrial-mediated apoptosis is induced by Hyp-PDT (24). As a key step in endogenous apoptosis, cytochrome $c$ is released from the mitochondria through the mitochondrial permeability transition pore, under the regulation of molecular signals, including members of the B-cell lymphoma-2 family (25). In the presence of dATP, cytochrome $c$ combines with apoptosis protease activating factor-1 (APAF-1) to form an apoptosome with APAF-1 and pro-caspase-9; and the latter is activated to cleaved caspase-9 (26). This can efficiently split the downstream apoptotic executioner caspase-3 to its active sub-units, and eventually induce apoptosis (21). In the present study, changes in cleaved caspase- 3 and cleaved caspase- 9 indicated that Hyp-PDT also induced potent mitochondrial-mediated apoptosis in the K562 human leukemia cells.

Apoptosis is a complex process involving various cellular factors and pathophysiologic pathways. As an indispensable component of the mitogen-activated protein kinase family, JNK is important in regulating apoptosis (27). The JNK pathway is activated predominantly by cell stressors, including ultraviolet radiation, heat shock and oxidative stress; as well as by proinflammatory cytokines, including tumor necrosis factor and interleukin-1 (27). Based on different cell types and stimuli, JNK may antipodally exert a pro-apoptotic or anti-apoptotic effect in mammals (28). For example, genipin, an aglycone derived from geniposide, can inhibit proliferation and induce apoptosis in K562 cells through JNK activation and induction of the Fas ligand (29); and CMS-9, a phospholipase A2 isolated from Naja nigricollis venom, activates the JNK pathway and stimulates mitochondrial apoptosis (30). The JNK inhibitor, SP600125, has been reported to prevent the release of cytochrome $c$ release and attenuate caspase- 9 and caspase- 3 activity (31).

Hyp has been reported to exert anti-inflammatory activities through attenuating the phosphorylation of JNK in rat peritoneal macrophages (32). Hyperoside, another active extract from Hypericumperforatum, can promote proliferation in ECV304 cells via the JNK pathway (33). However, the association between JNK and Hyp-PDT remains to be fully elucidated. The present study demonstrated for the first time, to the best of our knowledge, that the levels of p-JNK were upregulated $4 \mathrm{~h}$ following Hyp-PDT, prior to any increases in the levels of cleaved caspase- 9 and cleaved caspase- 3 were detected. The levels of p-JNK exhibited a marginal decrease at 8 and 16 h post-Hyp-PDT; however, the levels remained significantly higher than that of the control cells. It was hypothesized that the early increase in $\mathrm{p}-\mathrm{JNK}$, prior to changes in cleaved caspase- 9 and cleaved caspase-3, indicated that activation of the JNK pathway is the upstream regulator of Hyp-PDT-induced apoptosis. Further mechanistic investigations are required in order to confirm this hypothesis.

In conclusion, the results from the present study demonstrated that Hyp-PDT decreased cell viability in a light-intensity-, Hyp dose-, and irradiation-time-dependent manner. Mitochondria-mediated apoptosis was responsible for cell death, and activating the JNK pathway may be an important regulator. With the development of fiber-optic technology, laser medicine and extracorporeal circulation techniques, Hyp-PDT may be used as a novel therapeutic approach for leukemia.

\section{Acknowledgements}

This study was supported by the National Natural Science Foundation of China (grant no. 81200513), the Qianjiang Talents Project of Technology Office of Zhejiang Province (grant no. 2011R10049) and Wenzhou Science \& Technology Public Welfare Project (grant no. Y20140482).

\section{References}

1. Panzarini E, Inguscio V, Fimia GM and Dini L: Rose Bengal acetate photodynamic therapy (RBAc-PDT) induces exposure and release of damage-associated molecular patterns (DAMPs) in human HeLa cells. PLoS One 9: e105778, 2014.

2. Martirosyan AS, Vardapetyan HR, Tiratsuyan SG and Hovhannisyan AA: Biphasic dose-response of antioxidants in hypericin-induced photohemolysis. Photodiagnosis Photodyn Ther 8: 282-287, 2011.

3. Plaetzer K, Krammer B, Berlanda J, Berr F and Kiesslich T: Photophysics and photochemistry of photodynamic therapy: Fundamental aspects. Lasers Med Sci 24: 259-268, 2009.

4. Agostinis P, Berg K, Cengel KA, Foster TH, Girotti AW, Gollnick SO, Hahn SM, Hamblin MR, Juzeniene A, Kessel D, et al: Photodynamic therapy of cancer: An update. CA Cancer J Clin 61: 250-281, 2011.

5. Lee JY, Diaz RR, Cho KS, Lim MS, Chung JS, Kim WT, Ham WS and Choi YD: Efficacy and safety of photodynamic therapy for recurrent, high grade nonmuscle invasive bladder cancerrefractory or intolerant to bacille Calmette-Guérin immunotherapy. J Urol 190: 1192-1199, 2013.

6. Gray J and Fullarton GM: Long term efficacy of photodynamic therapy (PDT) as an ablative therapy of high grade dysplasia in Barrett's oesophagus. Photodiagnosis Photodyn Ther 10: 561-565, 2013.

7. Lo VC, Akens MK, Wise-Milestone L, Yee AJ, Wilson BC and Whyne CM: The benefits of photodynamic therapy on vertebral bone are maintained and enhanced by combination treatment with bisphosphonates and radiation therapy. J Orthop Res 31: 1398-1405, 2013

8. Krammer B and Verwanger T: Molecular response to hypericin-induced photodamage. Curr Med Chem 19: 793-798, 2012.

9. Nakajima N and Kawashima N: A basic study on hypericin-PDT in vitro. Photodiagnosis Photodyn Ther 9: 196-203, 2012.

10. Lima AM, Pizzol CD, Monteiro FB, Creczynski-Pasa TB, Andrade GP, Ribeiro AO and Perussi JR: Hypericin encapsulated in solid lipid nanoparticles: Phototoxicity and photodynamic efficiency. J Photochem Photobiol B 125: 146-154, 2013.

11. Ehrenberg B, Anderson JL and Foote CS: Kinetics and yield of singlet oxygen photosensitized by hypericin in organic and biological media. Photochem Photobiol 68: 135-140, 1998.

12. Kleemann B, Loos B, Scriba TJ, Lang D and Davids LM: St John's Wort (Hypericum perforatum L.) photomedicine: Hypericin-photodynamic therapy induces metastatic melanoma cell death. PLoS One 9: e103762, 2014.

13. Zheng Y,Le V, Cheng Z, Xie S, Li H, Tian J and Liu J: Development of rapid and highly sensitive HSPA1A promoter-driven luciferase reporter system for assessing oxidative stress associated with low-dose photodynamic therapy. Cell Stress Chaperones 18: 203-213, 2013.

14. Tan B,Anaka M,Deb S, Freyer C,Ebert LM, Chueh AC,Al-Obaidi S, Behren A, Jayachandran A, Cebon J, Chen W and Mariadason JM: FOXP3 over-expression inhibits melanoma tumorigenesis via effects on proliferation and apoptosis. Oncotarget 15: 264-276, 2014.

15. Miccoli L, Beurdeley-Thomas A, De Pinieux G, Sureau F, Oudard S, Dutrillaux B and Poupon MF: Light-induced photoactivation of hypericin affects the energy metabolism of human glioma cells by inhibiting hexokinase bound to mitochondria. Cancer Res 58: 5777-5786, 1998.

16. Chen B, Roskams T, Xu Y, Agostinis P and de Witte PA: Photodynamic therapy with hypericin induces vascular damage and apoptosis in the RIF-1 mouse tumor model. Int J Cancer 98: 284-290, 2002.

17. Roelants M, Van Cleynenbreugel B, Lerut E, Van Poppel H and de Witte PA: Human serum albumin as key mediator of the differential accumulation of hypericin in normal urothelial cell spheroids versus urothelial cell carcinoma spheroids. Photochem Photobiol Sci 10: 151-159, 2011. 
18. Kim HB, Kim MJ, Lee SH, Lee JW, Bae JH, Kim DW, Dao TT, Oh WK, Kang CD and Kim SH: Amurensin G, a novel SIRT1 inhibitor, sensitizes TRAIL-resistant human leukemic K562 cells to TRAIL-induced apoptosis. Biochem Pharmacol 84: 402-410, 2012

19. Fox FE, Niu Z, Tobia A and Rook AH: Photoactivated hypericin is an anti-proliferative agent that induces a high rate of apoptotic death of normal, transformed and malignant $\mathrm{T}$ lymphocytes: Implications for the treatment of cutaneous lymphoproliferative and inflammatory disorders. J Invest Dermatol 111: 327-332, 1998.

20. Rook AH, Wood GS, Duvic M, Vonderheid EC, Tobia A and Cabana B: A phase II placebo-controlled study of photodynamic therapy with topical hypericin and visible light irradiation in the treatment of cutaneous T-cell lymphoma and psoriasis. J Am Acad Dermatol 63: 984-990, 2010.

21. Berlanda J, Kiesslich T, Oberdanner CB, Obermair FJ, Krammer B and Plaetzer K: Characterization of apoptosis induced by photodynamic treatment with hypericin in A431 human epidermoid carcinoma cells. J Environ Pathol Toxicol Oncol 25: 173-188, 2006.

22. Buytaert E, Callewaert G, Hendrickx N, Scorrano L, Hartmann D, Missiaen L, Vandenheede JR, Heirman I, Grooten J and Agostinis P: Role of endoplasmic reticulum depletion and multidomain proapoptotic BAX and BAK proteins in shaping cell death after hypericin-mediated photodynamic therapy. FASEB J 20: 756-758, 2006.

23. Sanovic R, Krammer B, Grumboeck S and Verwanger T: Time-resolved gene expression profiling of human squamous cell carcinoma cells during the apoptosis process induced by photodynamic treatment with hypericin. Int J Oncol 35: 921-939, 2009.

24. Ali SM, Chee SK, Yuen GY and Olivo M: Hypocrellins and Hypericin induced apoptosis in human tumor cells: A possible role of hydrogen peroxide. Int J Mol Med 9: 461-472, 2002.
25. Koval J, Mikes J, Jendzelovský R, Kello M, Solár P and Fedorocko P: Degradation of HER2 receptor through hypericin-mediated photodynamic therapy. Photochem Photobiol 86: 200-205, 2010.

26. Skulachev VP: The programmed death phenomena, aging and the Samurai law of biology. Exp Gerontol 36: 995-1024, 2001.

27. Dhanasekaran DN and Reddy EP: JNK signaling in apoptosis. Oncogene 27: 6245-6251, 2008.

28. Varfolomeev EE and Ashkenazi A: Tumor necrosis factor: An apoptosis JuNKie?. Cell 116: 491-497, 2004.

29. Feng Q, Cao HL, Xu W, Li XR, Ren YQ and Du LF: Apoptosis induced by genipin in human leukemia K562 cells: Involvement of c-Jun N-terminal kinase in $\mathrm{G}_{2} / \mathrm{M}$ arrest. Acta Pharmacol Sin 32: 519-527, 2011

30. Chen YJ, Liu WH, Kao PH, Wang JJ and Chang LS: Involvement of p38 MAPK- and JNK-modulated expression of Bcl-2 and Bax in Naja nigricollis CMS-9-induced apoptosis of human leukemia K562 cells. Toxicon 55: 1306-1316, 2010.

31. Takamura M, Matsuda Y, Yamagiwa S, Tamura Y, Honda Y, Suzuki K, Ichida T and Aoyagi Y: An inhibitor of c-Jun $\mathrm{NH} 2$-terminal kinase, SP600125, protects mice from D-galactosamine/lipopolysaccharide-induced hepatic failure by modulating BH3-only proteins. Life Sci 80: 1335-1344, 2007.

32. Lee S, Park HS, Notsu Y, Ban HS, Kim YP, Ishihara K, Hirasawa N, Jung SH, Lee YS, Lim SS, et al: Effects of hyperin, isoquercitrin and quercetin on lipopolysaccharide-induced nitrite production in rat peritoneal macrophages. Phytother Res 22: 1552-1556, 2008

33. Zhang Z, Sethiel MS, Shen W, Liao S and Zou Y: Hyperoside downregulates the receptor for advanced glycation end products (RAGE) and promotes proliferation in ECV304 cells via the c-Jun N-terminal kinases (JNK) pathway following stimulation by advanced glycation end-products in vitro. Int J Mol Sci 14: 22697-22707, 2013. 